\title{
Chronic corticosterone exposure reduces hippocampal glycogen level and induces depression-like behavior in mice
}

\author{
Hui-yu ZHANG ${ }^{\dagger 1,2}$, Yu-nan ZHAO ${ }^{\dagger 1}$, Zhong-li WANG ${ }^{1}$, Yu-fang HUANG ${ }^{1}$ \\ ( ${ }^{1}$ Laboratory of Pathological Sciences, Basic Medical College, Nanjing University of Chinese Medicine, Nanjing 210023, China) \\ $\left({ }^{2}\right.$ Department of Pathology, School of Basic Medical Sciences, Guangzhou Medical University, Guangzhou 511436, China) \\ ${ }^{\dagger}$ E-mail: huiyuzhang615@126.com; zhaoyunan-js@163.com \\ Received June 17, 2014; Revision accepted Nov. 6, 2014; Crosschecked Dec. 26, 2014
}

\begin{abstract}
Long-term exposure to stress or high glucocorticoid levels leads to depression-like behavior in rodents; however, the cause remains unknown. Increasing evidence shows that astrocytes, the most abundant cells in the central nervous system (CNS), are important to the nervous system. Astrocytes nourish and protect the neurons, and serve as glycogen repositories for the brain. The metabolic process of glycogen, which is closely linked to neuronal activity, can supply sufficient energy substrates for neurons. The research team probed into the effects of chronic corticosterone (CORT) exposure on the glycogen level of astrocytes in the hippocampal tissues of male C57BL/6N mice in this study. The results showed that chronic CORT injection reduced hippocampal neurofilament light protein (NF-L) and synaptophysin (SYP) levels, induced depression-like behavior in male mice, reduced hippocampal glycogen level and glycogen synthase activity, and increased glycogen phosphorylase activity. The results suggested that the reduction of the hippocampal glycogen level may be the mechanism by which chronic CORT treatment damages hippocampal neurons and induces depression-like behavior in male mice.
\end{abstract}

Key words: Glycogen, Corticosterone, Stress, Depression, Hippocampus

doi:10.1631/jzus.B1400166 Document code: A CLC number: R749.4

\section{Introduction}

Depression is a polygenic and highly complex mood or affective disorder that causes people to persistently feel very sad. Chronic stress or psychological trauma is believed to be the major causal or exacerbating factor of depression. Neuroendocrine activity increases when exposed to strong and long-term physical and psychological stress stimuli, leading to hypothalamic-pituitary-adrenocortical (HPA) axis hyperactivity and elevated glucocorticoid levels. Increasing amounts of data suggest that the cortisol

\footnotetext{
Corresponding author

* Project supported by the National Natural Science Foundation of China (No. 81303246), the Jiangsu Provincial Natural Science Foundation of China (No. BK2011815), and the Qinglan Project of Jiangsu Province, China

levels of depressed patients are elevated, resulting in cognitive dysfunction and mood disorders (Zhao et al., 2012; Jarcho et al., 2013). Long-term subcutaneous corticosterone (CORT) injection can induce depression-like behavior in rodents (Zhao et al., 2008; Yau et al., 2011).

Studies have shown that synaptophysin (SYP) and neurofilament light protein (NF-L) expression levels, which are used in the neuronal structural plasticity index (Cotter et al., 2002), decrease in the hippocampal CA3 region after long-term stress or CORT injection (Zhao et al., 2009; Numakawa et al., 2013), leading to neuronal atrophy or loss (Banasr and Duman, 2008; Duric et al., 2013), which may be the underlying mechanism of stress or CORT-induced depression-like behavior. However, the mechanism underlying the decrease of neuronal structural plasticity remains unclear.

Astrocytes are the most abundant cells in the 
central nervous system (CNS). Astrocytes secrete neurotrophic and supportive factors that support, nourish, protect, and repair neurons (Rajkowska and Miguel-Hidalgo, 2007). Astrocytes regulate the uptake and clearance of transmitters across synapse gaps through amino acid neurotransmitter transporters, and thus are important for maintaining synaptic efficacy (Koizumi et al., 2003). Astrocytes nourish and protect neurons, as well as serve as energy repositories for the brain, because astrocytes store almost all the glycogen, an important energy reserve for the brain.

The potential importance of the CNS glycogen stores has recently received increased attention. Glycogen provides a material basis for astrocyte function and energy for neuronal activity and survival (Dombro et al., 2000; Dienel and Cruz, 2004). Studies on cell cultures have shown that increased amounts of glycogen in astrocytes can extend the lifespan of neurons (Brown et al., 2005). Brain glycogen may be an important source of energy substrates that support synaptic activity and maintain glutamatergic neurotransmission (Sickmann et al., 2012). Experiments of Brown et al. (2003) showed that glycogen is utilized to meet the energy needs of axons upon action potential propagation in optic nerve preparations, mainly by transferring lactate from astrocytes to axons. There are studies that indicate that glycogen mobilization is closely linked to neuronal activity and could supply enough energy substrates for neurons when energy substrates are inadequate (Brown et al., 2005). Reduction of brain glycogen is hypothesized herein to be associated with CORT-induced depressionlike behavior because glycogen in astrocytes is important to neuronal function.

\section{Materials and methods}

\subsection{Experimental animals}

The procedures of the present experiment were in accordance with the regulations set by the Committee on the Use of Live Animals in Research (Certificate No. 0025330; Permit No. SCXK (Su) 2012-0004), Laboratory Animal Center of Nanjing Medical University, China. Adult male C57BL/6N mice (18-20 g, 4-5 weeks, housed 5 mice per cage) were kept in a room on a standard 12-h light/dark cycle at $(25 \pm 1){ }^{\circ} \mathrm{C}$ and provided with food and water ad libitum. Mice were allowed one week to adapt to the laboratory environment before the actual experiments. The mice were treated in accordance with the Guidelines of Accommodation and Care for Animals by the Chinese Convention for the Protection of Vertebrate Animals used for Experimental and Other Scientific Purposes.

\subsection{CORT administration}

The mice were put into two groups (20 each group): control and CORT groups. The CORT group was conducted as described by Zhao et al. (2008). The animals in the CORT group received subcutaneous CORT injection $(20 \mathrm{mg} / \mathrm{kg})$ once per day $(5 \mathrm{ml} / \mathrm{kg})$ at random times during the light phase. The control animals received subcutaneous injections of the vehicle alone. All behavioral tests were performed during the day to avoid bias of dark-cycle locomotor activity changes. After four weeks (28 d) of administration, depression-like behavior in the mice was followed by the forced swim test (FST) and tail suspension test (TST). Ten animals from each group were randomly chosen, of which blood was collected for assessment and hippocampal tissues were used for Western blot analysis. The remaining animals were flash-frozen through rapid immersion in liquid nitrogen, of which hippocampal tissues were used for the glycogen assay and the enzyme assay. Five hours after the last dose of CORT, the mice were anesthetized using phenobarbital sodium and their cardiac blood was collected after injection of CORT on Day 29. Plasma was separated via centrifugation at $3000 \mathrm{r} / \mathrm{min}$ and stored at $-20{ }^{\circ} \mathrm{C}$ until needed for CORT concentration assay. The skull was opened and then the brain tissues were removed rapidly from the skulls. In order to expose the hippocampus, we need to remove the cerebral cortex covering it. The first incision is at the end of the hemisphere; the second incision is about $1.5-2.0 \mathrm{~mm}$ in front of the previous one and it should arrive at the lateral ventricle. Both incisions go to the brain's ventral part and meet there. The rest of the hippocampus is separated from the cortex covering it, along the surface towards the ventral part of the hippocampus. The brain tissues were rapidly removed after animals were subjected to rapid immersion in liquid nitrogen. The frozen hippocampal tissues were pulverized under liquid nitrogen using a mortar and a pestle for glycogen assay and enzyme activity assay. 


\subsection{Behavioral tests}

Behavioral tests were conducted in JLBehvFSG-4 sound insulation boxes controlled by a Dig Behav animal behavior video analysis system; this system can automatically record and analyze animal movements to provide total immobility time during the FST and TST. The FST test was conducted as described by Porsolt et al. (1978). The test was conducted in a 5000-ml glass beaker swim tank filled with $15 \mathrm{~cm}$-deep water at $(25 \pm 1){ }^{\circ} \mathrm{C}$. Each mouse was put separately and forced into a glass beaker for $6 \mathrm{~min}$. Behavior in the glass beaker swim tank was videotaped by a Dig Behav animal behavior video analysis system. Durations of immobility were videotaped during the last $4 \mathrm{~min}$. After $6 \mathrm{~min}$, the mouse was removed from the glass beaker. The TST test was conducted as described by Steru et al. (1985). At $24 \mathrm{~h}$ after the FST, the mice were individually suspended by securely taping the tail $1 \mathrm{~cm}$ from the tip, secured to a shelf $25 \mathrm{~cm}$ above the bottom of a sound insulation box. The mice should be hung for $6 \mathrm{~min}$, and the duration of immobility was videotaped during the last $4 \mathrm{~min}$.

\subsection{CORT assays}

Plasma CORT was measured using the commercial AssayMax CORT ELISA kit (Assaypro, Catalog No. EC3001-1). Each sample serum $(25 \mu \mathrm{l})$ and standard were loaded into microtiter plates, and then $25 \mu \mathrm{l}$ biotinylated CORT was added. After a 2-h incubation, plates were cleaned. Streptavidinperoxidase $(50 \mu \mathrm{l})$ was then added and incubated for $30 \mathrm{~min}$ at room temperature. After the substrate and stop solution were added, the optical density (absorbance at $450 \mathrm{~nm}$ ) was measured on a microplate reader (Molecular Devices, USA). The standard curve suggested a direct relationship between optical density and serum sample concentration.

\subsection{Western blot analysis}

The powdered hippocampal tissues were homogenized immediately at $4{ }^{\circ} \mathrm{C}$ in $0.5 \mathrm{ml}$ of lysis buffer. The solution was denatured in a sample buffer at $95{ }^{\circ} \mathrm{C}$ for $5 \mathrm{~min}$. The samples were then analyzed by $10 \%(0.1 \mathrm{~g} / \mathrm{ml})$ sodium dodecyl sulfate polyacrylamide gel electrophoresis (SDS-PAGE). The protein was transferred to membranes. The membrane was in turn incubated with a primary antibody, and biotin-tagged with a secondary antibody. The primary antibodies used to analyze protein expression are anti-SYP antibody (1:400 (v/v), Santa Cruz), anti-NF-L antibody (1:500 (v/v), Invitrogen), and anti- $\beta$-actin antibody (1:2000 (v/v), Sigma). The secondary antibodies were $\operatorname{IgG}(1: 4000(\mathrm{v} / \mathrm{v})$, Gene Script). The protein bands were analyzed with an FR-200A electrophoresis image analysis system. The SYP and NF-L levels of each sample were normalized against the $\beta$-actin from the same sample.

\subsection{Tissue glycogen assay}

Hippocampal glycogen assays were conducted as described by Kong et al. (2002). Briefly, powdered hippocampal tissues were separated into two samples (Fractions A and B). Two identical hippocampal powder portions from each sample were homogenized in $6 \%(0.06 \mathrm{~g} / \mathrm{ml})$ ice-cold perchloric acid, which instantly stops glycogen metabolism. Fraction A was treated with $100 \mu \mathrm{l}$ homogenate, $20 \mu \mathrm{l}$ of $1.0 \mathrm{~mol} / \mathrm{L} \mathrm{KHCO}_{3}, 1 \mathrm{ml}$ of $0.2 \mathrm{~mol} / \mathrm{L}$ sodium acetate, and $20 \mathrm{U} / \mathrm{ml}$ of amyloglucosidase; Fraction B was subjected to the same procedure, except the addition of $20 \mathrm{U} / \mathrm{ml}$ of amyloglucosidase. The reaction was terminated by adding $0.5 \mathrm{ml}$ of perchloric acid solution. The mixtures were centrifuged at $20000 \mathrm{r} / \mathrm{min}$ at $4{ }^{\circ} \mathrm{C}$ for $10 \mathrm{~min}$ and then neutralized by a $\mathrm{KOH}$ solution, and the resulting supernatants were used for the glucose assay. The glucose content was detected in 96-well plates, with $200 \mu$ reaction solution at $\mathrm{pH} 8.1$ in each well. The plates were laid in a fluorescence plate reader (SpectraMax Gemini, Molecular Devices, Menlo Park, CA, USA) and NADPH formation was measured at $355 \mathrm{~nm}$ excitation, $480 \mathrm{~nm}$ emission, and $420 \mathrm{~nm}$ cutoff wavelengths after shaking. The measurements were conducted after the incubation of 30 min with hexokinase added to each well. Desiccated glycogen hydrolyzed with $6 \%$ perchloric acid was found to exactly yield the predicted amount of glucose. Tissue glycogen levels, expressed as astrocyte glucose units ( $\mathrm{g} / \mathrm{g}$ wet tissue), were calculated by subtracting the final glucose concentrations in the unhydrolyzed tissues from those in the hydrolyzed tissues.

\subsection{Enzyme activity assay}

The powdered hippocampal tissues were homogenized in ice-cold lysis buffer $(1: 5, \mathrm{w} / \mathrm{v})$ at $\mathrm{pH}$ 7.5. 
The solution was centrifuged at $8000 \mathrm{r} / \mathrm{min}$ for $10 \mathrm{~min}$. The supernatants from the tissue were then used for the determination of glycogen synthase and glycogen phosphorylase activities.

\subsubsection{Glycogen synthase assay}

Glycogen synthase activity was assessed in hippocampal tissue from adult mice. The $20 \mu 1$ homogenates were added to $50 \mu \mathrm{l}$ reaction solution at $\mathrm{pH} 7.4$, for an incubation of $60 \mathrm{~min}$ at $38^{\circ} \mathrm{C}$, followed by adding $10 \mu \mathrm{l}$ of $0.5 \mathrm{~mol} / \mathrm{L} \mathrm{NaOH}$ solution to stop the reaction. A reaction solution $(1 \mathrm{ml})$ at $\mathrm{pH} 6.7$ was then added to each well for incubated of $20 \mathrm{~min}$. The plates were laid in the fluorescence plate reader at $340 \mathrm{~nm}$ excitation, $460 \mathrm{~nm}$ emission, and $420 \mathrm{~nm}$ cutoff wavelengths to measure NADH formation. Glycogen synthase levels in the tissues, expressed as astrocyte glycogen synthase units, were calculated as micromolar concentrations of glycogen synthase from astrocytes per gram of wet unhydrolyzed tissue.

\subsubsection{Glycogen phosphorylase assay}

Glycogen phosphorylase activity was assessed in hippocampal tissue from adult mice. The homogenates $(20 \mu \mathrm{l})$ were added to $180 \mu \mathrm{l}$ phosphate buffer at $\mathrm{pH} 6.8$ for an incubation of $10 \mathrm{~min}$ at $37^{\circ} \mathrm{C}$. The plates were laid in the fluorescence plate reader at $350 \mathrm{~nm}$ excitation, $470 \mathrm{~nm}$ emission, and $460 \mathrm{~nm}$ cutoff wavelengths to measure NADH formation. The reaction was activated with $2 \mathrm{mg} / \mathrm{ml}$ glycogen.

\subsection{Statistical analysis}

Data were expressed as the mean \pm standard error of the mean (SEM) with the number $(n)$ of experiments analyzed using SPSS 10.1. Differences between the groups were analyzed using the two-tailed Student's $t$-test. The significance level was set at $P \leq 0.05$ for all statistical comparisons.

\section{Results}

\subsection{Behavioral measurements}

Four weeks of CORT injections significantly lengthened the immobility time of the mice compared with the control group in FST and TST $(P<0.01$; Fig. 1).

\subsection{CORT measurements}

Repeated CORT injections led to a pronounced increase in the serum CORT level compared to that in control mice $(P<0.01 ; n=10$; Fig. 2$)$. Serum CORT levels increased about ten times in the CORT group in comparison with the control group.
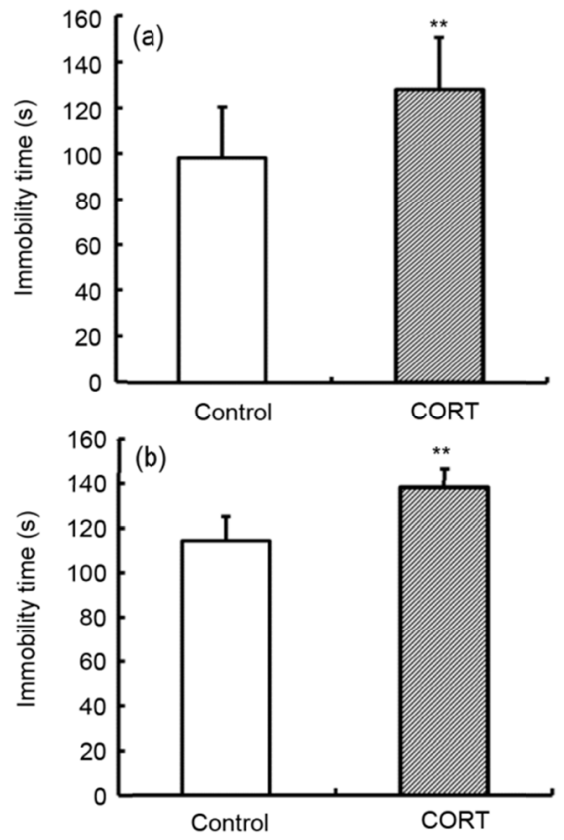

Fig. 1 Effects of repeated corticosterone (CORT) injection on depression-like behavior in male mice in the forced swim test (FST) and the tail suspension test (TST) $(n=20)$

The bars represent the mean immobility time ( \pm SEM) spent during the last 4 min of the FST (a) and TST (b). ${ }^{* *}$ denotes a significant difference at $P<0.01$

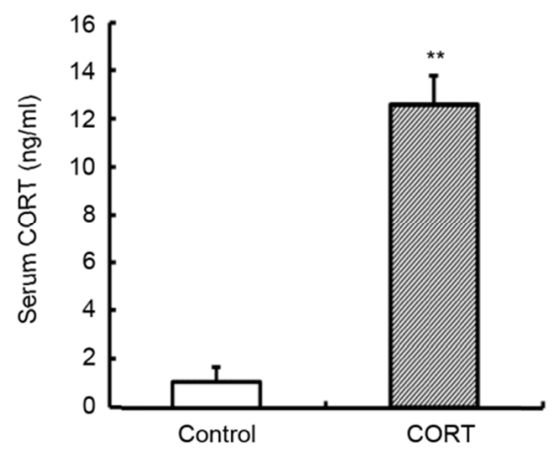

Fig. 2 Serum corticosterone (CORT) levels in the control and CORT-injected mice

The bars represent the mean $\pm \operatorname{SEM}(n=10)$. ${ }^{* *}$ denotes a significant difference at $P<0.01$ 


\subsection{Effects of CORT on hippocampal NF-L and SYP levels}

The effects of repeated CORT injections on hippocampal NF-L and SYP levels are presented in Fig. 3. Long-term CORT injections significantly decreased the NF-L and SYP $(P<0.01)$ levels in the hippocampus.

\subsection{Brain glycogen, glycogen synthase, and gly- cogen phosphorylase}

Glycogen levels in the hippocampal tissue were measured ( $n=10$ in each group; Fig. 4). Four weeks of CORT injections significantly reduced glycogen levels and glycogen synthase activities $(P<0.05)$, but significantly increased glycogen phosphorylase activities $(P<0.05)$.

\section{Discussion}

\subsection{Chronic CORT injection induces depression- like behavior in mice}

FST and TST have been widely used to examine CORT efficacy in inducing depression in rodents, where CORT has been shown to cause depressionlike behavior at high, but not low, doses, and by repeated, but not single, injections (Marks et al., 2009). Repeated CORT injections cause a gradual increase in depression-like behaviors (Zhao et al., 2008), especially in adolescent rats (Waters and McCormick, 2011). However, CORT may influence immobility behavior independent of the locomotor activity or muscle strength. To assess whether increased immobility behavior in the FST could be related to decreased locomotor activity or muscle strength,
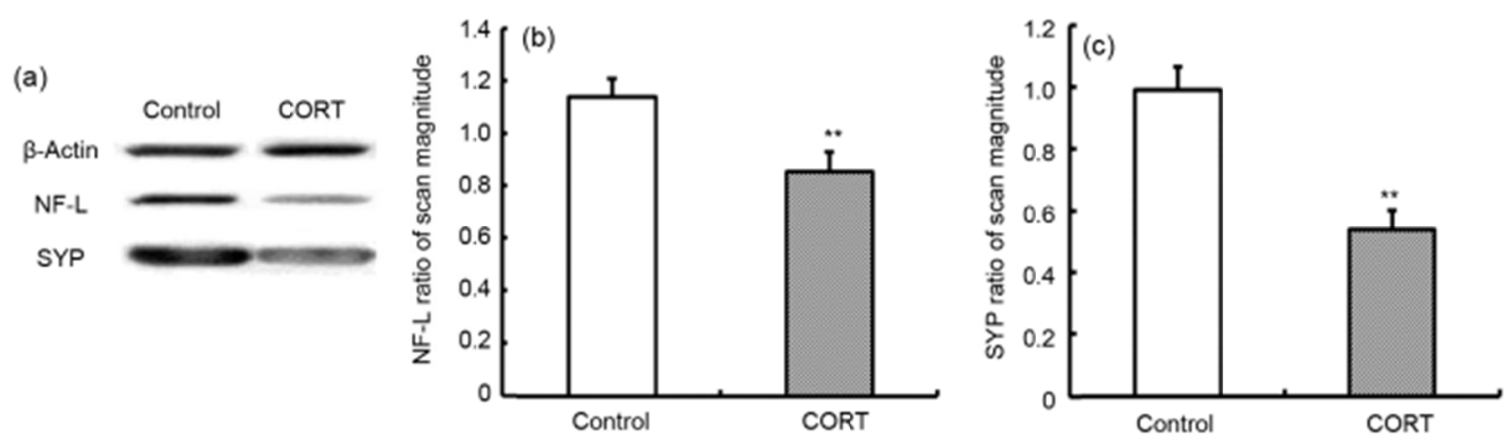

Fig. 3 Effects of repeated corticosterone (CORT) injections on neurofilament light protein (NF-L) and synaptophysin (SYP) levels in the hippocampal tissues of mice

Data are expressed as mean \pm SEM $(n=10)$. NF-L and SYP levels were determined by Western blot analysis using anti-NF-L, anti-SYP, and anti- $\beta$-actin antibodies (a). Proteins were separated on $12 \%$ SDS-PAGE and transferred to immuno-Blot PVDF membranes for the immunological assay. The protein bands were quantified using an FR-200A electrophoresis image analysis system. The values of NF-L (b) and SYP (c) levels were normalized to $\beta$-actin obtained in the same samples. ${ }^{* *}$ denotes a significant difference at $P<0.01$
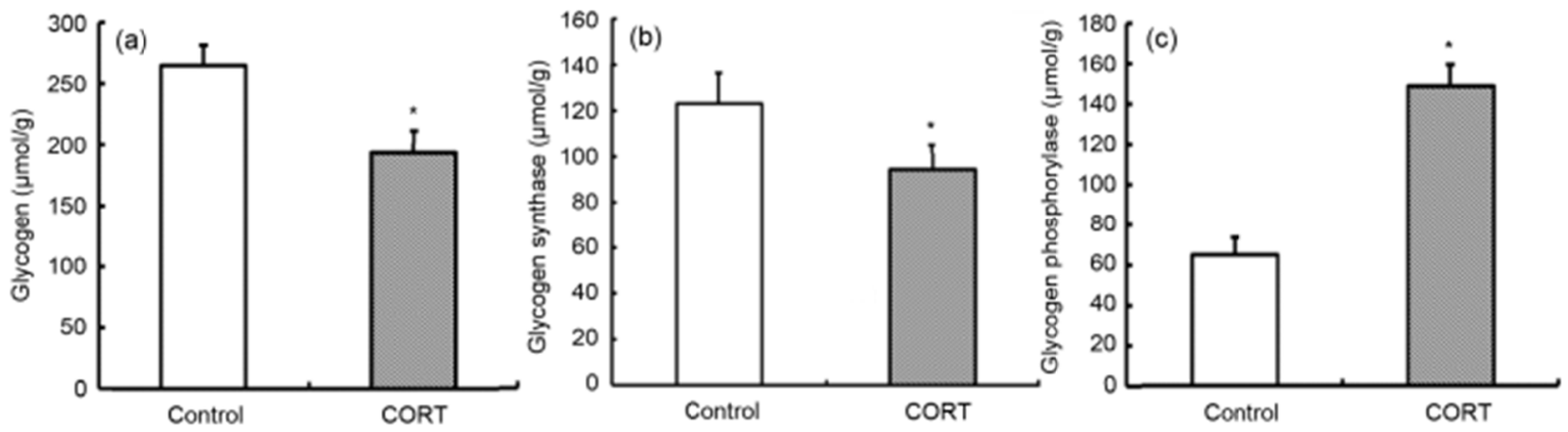

Fig. 4 Levels of brain glycogen (a), glycogen synthase (b), and glycogen phosphorylase (c) in the control and corticosterone (CORT)-treated mice

All data are expressed as mean \pm SEM $(n=10)$. Brain tissues used for the assay excluded the cerebellum and brainstem. denotes a significant difference at $P<0.05$ 
Marks et al. (2009) researched the effect of repeated CORT injections in an open-field test and in a wire suspension test. The results show that repeated CORT injections have no significant effect on locomotor activity or muscle strength, suggesting that CORTinduced depressogenic effects occur independently of changes in nonspecific motor behavior. Repeated CORT injections have recently been considered reliable to study chronic stress-induced depression in rodents. Four-week CORT injections were also found in this study to greatly increase serum CORT levels and depression-like behavior in male mice both in the FST and the TST $(P<0.01)$. This is similar to the study of Zhao et al. (2008) and further confirms that long-term exposure to high CORT levels could cause depression-like behavior in rodents.

\subsection{Long-term CORT injection damages the structural plasticity of hippocampal neurons}

Yau et al. (2011) found that CORT inhibits neurogenesis, thereby reducing hippocampal spine density and causing spatial learning disorders. SYP is an indicator of synapses and synaptic transmission efficiency, and NF-L is involved in maintaining normal morphology and motor function of neurons, the spatial configuration of axons, and nerve signal transduction. Our results showed that the two proteins were significantly decreased $(P<0.01)$, further confirming that long-term elevated glucocorticoid is detrimental to hippocampal plasticity.

\subsection{Long-term CORT injection reduces hippo- campal glycogen levels}

Glycogen is most frequently localized to astrocytes (Pfeiffer-Guglielmi et al., 2003), not evenly distributed throughout the brain. An electron microscopic study of glycogen granules in the brain shows that glycogen is concentrated in the part with the greatest synaptic density, suggesting that brain glycogen plays a role in the energy-dependent process of synaptic transmission (Xu and Sun, 2010).

Neurons are sensitive to energy shortages and have limited energy reserves. The ability to absorb sugar is thus critical for continuation of normal neuronal function. The main energy substrate sources of neurons are glucose. Glucose enters into astrocytes, and generates glycogen stored. The glycogen can be rapidly metabolized to provide energy substrates when they are needed by neurons. Glycogen stored in astrocytes also provides additional energy for neurons when in great need (Suzuki et al., 2011). Our study showed that the hippocampal glycogen content in CORT-injected mice decreased significantly compared with the controls. Glucocorticoids decrease glycogen stored in cultured astrocytes (Allaman et al., 2004). Tsoi et al. (2011) showed that restraint stress could lead to glucose metabolism disorder, which decreases glycogen content.

Changes of the glycogen content in astrocytes may significantly alter brain energy metabolism, because glycogen is the largest energy reserve in the CNS and glycogen level reduction directly affects astrocyte metabolism and function. Astrocytes have an important nutritional role for neurons. Changes of the glycogen in astrocyte down-regulate neuronal function and directly affect neuronal metabolism. When astrocytes cannot supply glycogen to the brain to provide energy in a timely manner, neurons atrophy and die. If glycogen content in the CNS decreases, neurotransmitters and action potentials will be immediately and seriously affected. Brain glycogen shortage may therefore directly compromise the structure and function of astrocyte, causing astrocyte atrophy, which will in turn worsen the neuronal energy crisis, increase the apoptosis potential, and reduce the neuronal excitability (Ibrahim et al., 2011), thereby resulting in depression.

\subsection{Reduction of hippocampal glycogen levels is due to decreased glycogen synthesis and increased glycogenolysis}

Tesfaye et al. (2011) showed that the glycogen content is affected by several factors, such as glucose, insulin, neurotransmitters, and neuronal activation. The key enzymes regulating synthesis and degradation of brain glycogen, glycogen synthase and glycogen phosphorylase, are contrastingly regulated by phosphorylation. Glycogen is synthetized from glucose by glycogen synthase, which catalyzes the formation of $\alpha-1,4$-glycosidic linkage in the polymer, and the glycogen branching enzyme. Degradation occurs in the cytosol through glycogen phosphorylase and the debranching enzyme (Greenberg et al., 2006; Palsamy and Subramanian, 2009). Chronic CORT injection was found to increase glycogen phosphorylase activity, indicating increased glycogenolysis, but 
reduce glycogen synthase activity.

Glucocorticoid hormones modulate energy supply (Russell et al., 2006). Glucocorticoids not only can inhibit glucose transfer to neurons and astrocytes but also can curb the noradrenergic activity to reduce glycogen synthesis (Allaman et al., 2004). Astrocyte activity may thus be down-regulated by increased HPA activity in stressful situations. High glucocorticoid levels acting on astrocytes impair glycogen replenishment, deplete energy reserves, and reduce lactate transport.

\section{Conclusions}

The results showed that chronic CORT injection decreased hippocampal glycogen level and glycogen synthase activity, but increased glycogen phosphorylase activity. Chronic CORT injection also reduced NF-L and SYP levels in mice. Our study suggested that reduced glycogen levels may be one of the reasons why chronic CORT treatment caused hippocampus atrophy and depression-like behavior in male mice.

\section{Compliance with ethics guidelines}

Hui-yu ZHANG, Yu-nan ZHAO, Zhong-li WANG, and Yu-fang HUANG declare that they have no conflict of interest.

All institutional and national guidelines for the care and use of laboratory animals were followed.

\section{References}

Allaman, I., Pellerin, L., Magistretti, P.J., 2004. Glucocorticoids modulate neurotransmitter-induced glycogen metabolism in cultured cortical astrocytes. J. Neurochem., 88(4):900-908. [doi:10.1046/j.1471-4159.2003.02235.x]

Banasr, M., Duman, R.S., 2008. Glial loss in the prefrontal cortex is sufficient to induce depressive-like behaviors. Biol. Psychiatry, 64(10):863-870. [doi:10.1016/j.biopsych. 2008.06.008]

Brown, A.M., Tekkök, S.B., Ransom, B.R., 2003. Glycogen regulation and functional role in mouse white matter. J. Physiol., 549(2):501-512. [doi:10.1113/jphysiol.2003. 042416]

Brown, A.M., Sickmann, H.M., Fosgerau, K., et al., 2005. Astrocyte glycogen metabolism is required for neural activity during aglycemia or intense stimulation in mouse white matter. J. Neurosci. Res., 79(1-2):74-80. [doi:10. 1002/jnr.20335]

Cotter, D., Mackay, D., Chana, G., et al., 2002. Reduced neuronal size and glial cell density in area 9 of the dorsolateral prefrontal cortex in subjects with major de- pressive disorder. Cereb. Cortex, 12(4):386-394. [doi:10. 1093/cercor/12.4.386]

Dienel, G.A., Cruz, N.F., 2004. Nutrition during brain activation: does cell-to-cell lactate shuttling contribute significantly to sweet and sour food for thought? Neurochem. Int., 45(2-3):321-351. [doi:10.1016/j.neuint.2003.10.011]

Dombro, R.S., Bender, A.S., Norenberg, M.D., 2000. Association between cell swelling and glycogen content in cultured astrocytes. Int. J. Devl. Neurosci., 18(2-3):161-169. [doi:10.1016/S0736-5748(99)00084-2]

Duric, V., Banasr, M., Stockmeier, C.A., et al., 2013. Altered expression of synapse and glutamate related genes in post-mortem hippocampus of depressed subjects. Int. J. Neuropsychopharmacol., 16(1):69-82. [doi:10.1017/S14 61145712000016]

Greenberg, C.C., Jurczak, M.J., Danos, A.M., et al., 2006. Glycogen branches out: new perspectives on the role of glycogen metabolism in the integration of metabolic pathways. Am. J. Physiol. Endocrinol. Metab., 291(1): E1-E8. [doi:10.1152/ajpendo.00652.2005]

Ibrahim, L., Duncan, W., Luckenbaugh, D.A., et al., 2011. Rapid antidepressant changes with sleep deprivation in major depressive disorder are associated with changes in vascular endothelial growth factor (VEGF): a pilot study. Brain Res. Bull., 86(1-2):129-133. [doi:10.1016/j. brainresbull.2011.06.003]

Jarcho, M.R., Slavich, G.M., Tylova-Stein, H., et al., 2013. Dysregulated diurnal cortisol pattern is associated with glucocorticoid resistance in women with major depressive disorder. Biol. Psychol., 93(1):150-158. [doi:10. 1016/j.biopsycho.2013.01.018]

Koizumi, S., Fujishita, K., Tsuda, M., et al., 2003. Dynamic inhibition of excitatory synaptic transmission by astrocytederived ATP in hippocampal cultures. PNAS, 100(19): 11023-11028. [doi:10.1073/pnas.1834448100]

Kong, J., Shepel, P.N., Holden, C.P., et al., 2002. Brain glycogen decreases with increased periods of wakefulness: implications for homeostatic drive to sleep. J. Neurosci., 22(13):5581-5587.

Marks, W., Fournier, N.M., Kalynchuk, L.E., 2009. Repeated expore to corticosterone increases depression-like behavior in two different versions of the forced swim test without altering nonspecific locomotor activity or muscle strength. Physiol. Behav., 98(1-2):67-72. [doi:10.1016/j. physbeh.2009.04.014]

Numakawa, T., Adachi, N., Richards, M., et al., 2013. Brainderived neurotrophic factor and glucocorticoids: reciprocal influence on the central nervous system. Neuroscience, 239:157-172. [doi:10.1016/j.neuroscience.2012.09. 073]

Palsamy, P., Subramanian, S., 2009. Modulatory effects of resveratrol on attenuating the key enzymes activities of carbohydrate metabolism in streptozotocin-nicotinamideinduced diabetic rats. Chem. Biol. Interact., 179(2-3): 356-362. [doi:10.1016/j.cbi.2008.11.008]

Pfeiffer-Guglielmi, B., Fleckenstein, B., Jung, G., et al., 2003. 
Immunocytochemical localization of glycogen phosphorylase isozymes in rat nervous tissues by using isozyme-specific antibodies. J. Neurochem., 85(1):73-81. [doi:10.1046/j.1471-4159.2003.01644.x]

Porsolt, R.D., Anton, G., Blavet, N., et al., 1978. Behavioral despair in rats: a new model sensitive to antidepressant treatments. Eur. J. Pharmacol., 47(4):379-391. [doi:10. 1016/0014-2999(78)90118-8]

Rajkowska, G., Miguel-Hidalgo, J.J., 2007. Gliogenesis and glial pathology in depression. CNS Neurol. Disord. Drug Targets, 6(3):219-233. [doi:10.2174/187152707780619326]

Russell, V.A., Oades, R.D., Tannock, R., et al., 2006. Response variability in Attention-Deficit/Hyperactivity Disorder: a neuronal and glial energetics hypothesis. Behav. Brain Funct., 2:30. [doi:10.1186/1744-9081-2-30]

Sickmann, H.M., Waagepetersen, H.S., Schousboe, A., et al., 2012. Brain glycogen and its role in supporting glutamate and GABA homeostasis in a type 2 diabetes rat model. Neurochem. Int., 60(3):267-275. [doi:10.1016/j.neuint. 2011.12.019]

Steru, L., Chermat, R., Thierry, B., et al., 1985. The tail suspension test: a new method for screening antidepressants in mice. Psychopharmacology, 85(3):367-370. [doi:10. 1007/BF00428203]

Suzuki, A., Stern, S.A., Bozdagi, O., et al., 2011. Astrocyteneuron lactate transport is required for long-term memory formation. Cell, 144(5):810-823. [doi:10.1016/j.cell. 2011.02.018]

Tesfaye, N., Seaquist, E.R., Oz, G., 2011. Noninvasive measurement of brain glycogen by nuclear magnetic resonance spectroscopy and its application to the study of brain metabolism. J. Neurosci. Res., 89(12):1905-1912. [doi:10. 1002/jnr.22703]

Tsoi, B., He, R.R., Yang, D.H., et al., 2011. Carnosine ameliorates stress-induced glucose metabolism disorder in restrained mice. J. Pharmacol. Sci., 117(4):223-229. [doi:10.1254/jphs.11131FP]

Waters, P., McCormick, C.M., 2011. Caveats of chronic exogenous corticosterone treatments in adolescent rats and effects on anxiety-like and depressive behavior and hypothalamic-pituitary-adrenal (HPA) axis function. Biol. Mood Anxiety Disord., 1(1):4. [doi:10.1186/2045-5380-1-4]

$\mathrm{Xu}, \mathrm{L}$., Sun, H., 2010. Pharmacological manipulation of brain glycogenolysis as a therapeutic approach to cerebral ischemia. Mini-Rev. Med. Chem., 10(12):1188-1193. [doi:10.2174/1389557511009011188]
Yau, S.Y., Lau, B.W., Tong, J.B., et al., 2011. Hippocampal neurogenesis and dendritic plasticity support runningimproved spatial learning and depression-like behaviour in stressed rats. PLOS ONE, 6(9):e24263. [doi:10.1371/ journal.pone.0024263]

Zhao, Y., Ma, R., Shen, J., et al., 2008. A mouse model of depression induced by repeated corticosterone injections. Eur. J. Pharmacol., 581(1-2):113-120. [doi:10.1016/j. ejphar.2007.12.005]

Zhao, Y., Xie, W., Dai, J., et al., 2009. The varying effects of short-term and long-term corticosterone injections on depression-like behavior in mice. Brain Res., 1261:82-90. [doi:10.1016/j.brainres.2008.12.083]

Zhao, Y., Wang, Z., Dai, J., et al., 2012. Beneficial effects of benzodiazepine diazepam on chronic stress-induced impairment of hippocampal structural plasticity and depression-like behavior in mice. Behav. Brain Res., 228(2):339-350. [doi:10.1016/j.bbr.2011.12.013]

\section{中文概要}

题 目: 慢性皮质酮降低海马糖原水平及诱导小鼠抑郁样 行为

目 的：探讨慢性皮质酮（CORT）注射对脑糖原水平以 及小鼠抑郁样行为的影响。

创新点: 首次发现长期注射皮质酮可减少海马糖原浓度, 降低糖原合酶活性, 但增加糖原磷酸化酶活性。

方 法: 将 40 只雄性 C57BL/6N 小鼠随机分为正常对照组 与模型组。对模型组小鼠进行连续四周的 CORT 皮下注射, 构建慢性应激抑郁障碍小鼠模型。采 用强迫游泳和悬尾实验, 验证慢性应激模型的建 立; 采用放免法, 测定小鼠血清中 CORT 水平; 采用蛋白免疫印迹法, 检测海马神经微丝轻链

（NF-L）和突触囊泡蛋白（SYP）的表达水平; 采用酶法, 检测海马组织的糖原浓度以及糖原合 成酶和糖原磷酸化酶的活性。

结 论: 慢性 CORT 注射引起的海马神经元损伤和诱导小 鼠抑郁样行为, 可能与 CORT 降低海马糖原水平 有关。

关键词: 皮质酮; 应激; 抑郁症; 糖原; 海马 